\title{
Assessing Organic Cherry Farmers' Strategies under Different Policy Options
}

\author{
Irene Tzouramani ${ }^{1}$, Angelos Liontakis' ${ }^{1}$, Alexandra Sintori' ${ }^{1}$, George Alexopoulos ${ }^{2}$ \\ ${ }^{1}$ Agricultural Economics and Policy Research Institute, Hellenic Agricultural Organisation (DEMETER), Athens, \\ Greece \\ ${ }^{2}$ Department of Agricultural Economics and Rural Development, Agricultural University of Athens, Athens, \\ Greece \\ Email: tzouramani@agreri.gr, aliontakis@agreri.gr, al_sintori@agreri.gr, galexop@aua.gr
}

Received 13 February 2014; revised 13 March 2014; accepted 20 March 2014

Copyright (C) 2014 by authors and Scientific Research Publishing Inc.

This work is licensed under the Creative Commons Attribution International License (CC BY).

http://creativecommons.org/licenses/by/4.0/

(c) (i) Open Access

\begin{abstract}
Organic farming has experienced a vast increase within the EU. Especially in Greece, the rapid growth of the organic sector, since the early ' 90 s, was accompanied by the introduction of various organic crops. Among them, organic fruit crops have been gradually introduced, as farmers have realised the promising growth of the demand for organic fruits. However, organic farmers face significant yield and price risks, which combined with the high initial establishment costs, provoke difficult investment decisions. Rational farmers are willing to adopt organic farming only if the economic outcomes outweigh the associated increased risk and uncertainty. This study employs stochastic efficiency analysis to compare the economic outcomes of organic and conventional cherry production in Northern Greece. It, thus, explores whether the expansion of organic cherry production generates satisfactory economic results for farmers and whether it can be regarded as a promising alternative to conventional production activity. Results reveal that the current Greek policy scheme may endanger investments in organic cherry farming. Further assessment of the impact of varying organic subsidy and discount rate levels on the net present value underlines the detrimental effects of the financial crisis. An enhanced policy framework is required to enable and support climate-smart agriculture.
\end{abstract}

\section{Keywords}

Organic Agriculture, Cherry Sector, Agricultural Policy, Stochastic Simulation, SERF Analysis

\section{Introduction}

Organic farming has vastly increased in European countries during recent decades. The robust demand for quality

How to cite this paper: Tzouramani, I., et al. (2014) Assessing Organic Cherry Farmers' Strategies under Different Policy Options. Modern Economy, 5, 313-323. http://dx.doi.org/10.4236/me.2014.54031 
products, the development of the market and supportive institutional frameworks are the driving forces for smart, sustainable European agriculture [1]. This trend is expected to continue, as the growth in demand for organic products steadily outpaces the corresponding supply even during the current financial recession [2]. European organic farmland reached 7.6 million hectares (ha) in 2008, which corresponds to $4.1 \%$ of the total utilized agricultural area (UAA) and accounts for almost 190,000 active holdings in the sector. In Greece, the organic sector has experienced even more rapid growth, as organically cultivated area increased from 591 ha in 1993 to 309,822 ha in 2010 ( $8.2 \%$ of the UAA) [3]. The structure of the 24,000 organic holdings primarily consists of arable crops (27.4\%), permanent crops (21.5\%) and permanent pasture (49.0\%) [3]. This portfolio depicts a significant change in the make-up of organic production since its early phase in the 1990s, when permanent crops were the main organic production category and organic olive trees (62.1\%), vineyards (11.1\%) and citrus fruits (7.5\%) were dominant. Today, the diversification of organic crops has been increasing as crops with superior market prospects such as cereals $(11.4 \%)$, forages $(9.6 \%)$, and vegetables and fruits $(1.3 \%)$ have gradually been introduced.

Recent data confirm that fruits and vegetables are the most important category of organic products that consumers purchase [1] [2] [4]. The growing demand for organic fruits creates new opportunities for Greek farmers who have opted for the production of organic cherries. Greek cherry producers have recently followed an exportoriented policy to reach new markets and have gradually managed to build their commercial links and strengthen their presence in European markets. This strategy is the outcome of a carefully designed and systematically implemented approach in the areas of standardisation, promotion and post-harvest physiology. These solutions were offered to producers who had adopted innovative farm practices, modernised their farms, and introduced new cherry varieties [5]. The interest of Greek farmers in organic cherry production appears to be equally as strong as interest in conventional production despite the increased risk and uncertainty involved.

Today, organic cherry production in Greece is limited and covers only 138 ha. The total area for cherry cultivation is 9700 ha, accounting for the production of approximately 42,000 tonnes of cherries in the last decade. The main cherry-producing areas are in Northern Greece and, more specifically, in the region of Central Macedonia, where $77.9 \%$ of cherry orchards and $64.2 \%$ of total cherry production are located. In the last decade, the number of trees has shown an upward trend. The average production increased by $23 \%$ from 37,122 tonnes (2001-2005) to 45,892 tonnes (2006-2010) [6]. An upward trend in the farm-gate price of cherries was the main driving factor behind the modernisation and restructuring of the sector. Consumers' perceptions of the health-promoting properties of cherries (due to their high antioxidant activity) [7] and the high convenience level of cherries [8] create favourable conditions for the further development of the sector. Farmers have recently introduced new varieties that satisfy consumer preferences and simultaneously expand the production period. These new varieties cover observed gaps during the picking period and produce higher-quality products with increased export potential. Moreover, agricultural cooperatives and producer organisations have applied advanced technological systems for post-harvest treatments that prevent quality loss, expand the timing of supply and ultimately maximise returns.

This study explores whether the expansion of organic cherry production generates satisfactory economic results for farmers and whether it can thus be regarded as a promising alternative productive activity. Cherry farmers face significant yield and price risks, which, combined with the high initial cost of orchard establishment, provoke difficult investment decisions. This study applies the stochastic efficiency with respect to a function (SERF), introduced by Hardaker et al. [9], to account for the risk and uncertainty of such investments. Therefore, the evaluation of the farmers' option of turning to organic cultivation, under risk and uncertainty, reveals the real dimensions of such an attempt and allows for policy suggestions that could facilitate farmers' decisions.

In addition, this study explores the consequences of the exclusion of the fruit sector from the Greek organic policy scheme on the economic outcomes of organic cherry producers. We thus perform a sensitivity analysis to investigate the economic outcomes of organic cherry production under various levels of subsidies. To explore the consequences of the financial crisis on the risky investment decisions, we also perform a sensitivity analysis on changes in the net present value caused by increases in the discount rate level.

The remainder of the paper is organised as follows: The next two sections describe the applied methodology and data sources that are used in the study. The empirical application of SERF analysis is then illustrated and discussed. Finally, the paper concludes with a summary of the main findings, a discussion regarding the investment strategies of Greek organic cherry farmers and critical suggestions for agricultural policy planners. 


\section{Methodology}

Analysing cherry farmers' decision making entails understanding how they rank activities with uncertain outcomes, given the stochastic yield of cherry orchards and the stochastic market price of cherries. The economic evaluation of organic and conventional cherry production is implemented considering the whole range of net present values (NPVs) and their associated probabilities, along with the relative preferences (utilities) of the decision makers. To assess and compare the economics and the risk efficiency of conventional and organic cherry production, this study employs stochastic simulation as an unconventional method that incorporates risk [10]. Stochastic dominance and stochastic efficiency with respect to a function (SDRF and SERF) analyses have a major advantage in that they reduce the set of all possible risky choices to a small group of alternatives. The SERF technique is a novel improved methodology for assessing and ranking risky alternatives but empirical studies using SERF are limited, Especially in agriculture, SDRF and SERF analyses have been used to compare risky alternatives regarding farm production, marketing and financial matters [11]. In Greece, SERF analysis has been used by Tzouramani et al. [12] to determine risk efficiency between organic and conventional lemons and citrus cultivation and by Tzouramani et al. [13], to explore the economic viability of conventional and organic sheep farming.

Let us assume that a farmer has to decide whether to invest in organic $\left(f_{o}\right)$ or in conventional $\left(g_{c}\right)$ cherry production, with his cumulative distribution function of NPVs given by $F_{o}(x)$ and $G_{c}(x)$, respectively. Organic farming dominates over conventional farming, in the sense of first-order stochastic dominance (FSD), if $G_{c}(x)-F_{o}(x) \geq 0 \quad \forall x \in \Re$, with strict inequality for some $x \in \mathfrak{R}$ [14]. This means that farm operators prefer more NPV to less. The decision maker will select the action associated with a cumulative density function that always lies to the right, provided that distributions do not intersect.

If we consider investors to be risk averse, a selection between distributions could be made using the second-order stochastic dominance criterion (SSD). The SSD assumes that the decision maker prefers more income to less and does not prefer risk. Formally, organic cherry production dominates conventional production, in the SSD sense, if $\int_{-\infty}^{x} G_{c}(x)-F_{o}(x) d x \geq 0 \forall x \in \Re$, with strict inequality for some $x \in \mathfrak{R}$ [15]. In other words, the SSD criterion requires that the area under the cumulative density function for organic farming always be smaller than the area under the cumulative density function for conventional farming. However, empirical studies often conclude that the SSD is not discriminating enough to yield useful results [10].

To rank risky scenarios for conventional and organic cherry production, we apply the stochastic efficiency with respect to a function (SERF) analysis. SERF analysis allows for the comparison of risky alternatives and gives a graphical representation of results with different risk preferences in a transparent way [10]. All scenarios were analyzed across a wide spectrum of risk preferences, ranging from risk neutral to extremely risk averse decision makers (using relative risk aversion coefficients from 0 to 4 ). A power utility function was assumed, as the risky distributions change over a multiple-year planning horizon [9].

SERF computes the certainty equivalent (CE) over a range of relative risk aversion coefficients. The CE is equal to the amount of payoff a farmer would require to be indifferent between that payoff and a risky investment. In this case, the organic (F) and conventional (G) farming systems can be compared and ranked at each relative risk aversion coefficient $\left(\operatorname{RRAC}_{\mathrm{i}}\right)$, and $F_{o}(x)$ is preferred to $G_{c}(x)$ at $R R A C_{i}$ if $C E_{F_{o i}} \succ C E_{G_{c i}}$. The CEs are readily interpreted because, unlike utility values, they are expressed in monetary terms. For a risk-averse decision maker, the estimated CE is typically less than the expected money value. The difference between the expected money value and the CE is the risk premium [9] [16], which reflects the minimum amount that would have to be paid to a decision maker to justify a switch from conventional to organic production.

A stochastic simulation model was built to estimate the NPV of conventional and organic cherry production. The stochastic model was based on deterministic enterprise budgets per hectare for each activity. The stochastic variables were then introduced to the model to take into account the uncertainty of cherry prices and yields. The simulation model is presented below:

$$
N P V=\sum_{i=1}^{T} \frac{\left(\tilde{Y}_{i} * \tilde{P}_{i}\right)+S-V C_{i}-I_{i}}{(1+\rho)^{i}}
$$

where

NPV: Net present value of organic or conventional cherry production in year $i$ 
$I_{i}$ : Establishment cost of organic or conventional cherry production in year $i$

$\tilde{Y}_{i}$ : Stochastic yield for organic or conventional cherry production in year $i$

$\tilde{P}_{i}$ : Stochastic price for organic or conventional cherries in year $i$

$S$ : Subsidies for (organic) cherry production

$V C_{i}$ : Variable cost for organic or conventional cherry production in year $i$

$\rho$ : Discount rate

$T$ : Expected life

In the next section, we describe in detail the estimation of each parameter of the simulation model. It is also important to mention that the single farm payment and the compensation payment for mountainous and less favoured areas have not been taken into account, as these subsidies are not linked to a certain production activity. On the other hand, the subsidies for organic cherry production under the previous policy scheme are incorporated into the model, as the level of payment per hectare can be estimated. It should be mentioned that while the former policy scheme supported cherry producers with $900 € /$ ha, the current policy scheme does not provide any such subsidy. To assess the impact of this policy scheme, we also run a sensitivity analysis on the NPVs obtained by three different levels of organic subsidy. Specifically, we examine subsidy levels equal to a) $450 € /$ ha (50\% reduction), b) $300 € /$ ha (66.7\% reduction) and c) $150 € /$ ha (83.3\% reduction).

\section{Data}

Two investment options, organic and conventional cherry production, were evaluated. This evaluation requires data on the establishment cost, operating production costs and costs of capital, as well as information regarding the returns of each option. Data used in this analysis were obtained from face-to-face interviews with 50 cherry producers located in the most important and traditional cherry-producing Greek prefectures, Pella and Imathia. Thirty-five of the interviewees are conventional cherry producers who were randomly selected, whereas the remaining 15 producers constitute the entire population of organic producers in the area when the field survey was conducted (2007-2008). This research was funded by the European Tobacco Fund (Measure 9, Reg (EU) 2182/02) under the research project "Search for Innovative Occupations of Tobacco Producers in the Rural Sector, in Greece".

\subsection{Establishment Cost}

Cherries are a perennial crop with a significant establishment (sunk) cost. This cost includes the cherry seedlings, the soil preparation, the labour and land remuneration, the irrigation system and the interest rates for the pre-productive period. For the proper estimation of the above costs, the collected information was combined with expert suggestions and advice of local agriculturalists. Cherry trees require approximately five years to yield an initial commercial harvest. The value of an orchard at the end of the fifth year reflects the total invested capital. According to Table 1, this value is 13,390 €/ha for conventional production and 10,495 €/ha for organic production. An organic orchard's value is about $25 \%$ lower than the value of a conventional one due to the lower organic production costs. The productive life of a cherry orchard ranges from 25 to 50 years depending on the cultivated variety [17] [18]. In this analysis, given the cultivation practices in the area under study and expert advice, we assume a productive life of 25 years.

\subsection{Cost of Production}

The annual production costs for both organic and conventional cherry production were calculated in accordance with their deterministic enterprise budgets (Table 2). The production cost for conventional cherries is $25.25 \%$ higher than for organic cherries, indicating a more intensive production system. The most important element of the conventional cherry production cost is the labour cost (49.19\%), which is $71.42 \%$ greater than that of organic production, as conventional production demands more labour (due to higher yields) during the harvesting season, more field operations (such as pesticide and fertilizer applications) and more intensive pruning and irrigation. Capital cost is also an important element of total cost in both activities. The purchasing cost of fertilizers and pesticides constitutes almost half of the capital cost. In the case of conventional production, this is due to the large quantity of inputs used, whereas in the case of organic production, this is due to the high price of certified organic pesticides and herbicides. 
Table 1. Establishment cost for conventional (Con) and organic (Org) cherry orchards in Greece (€/ha).

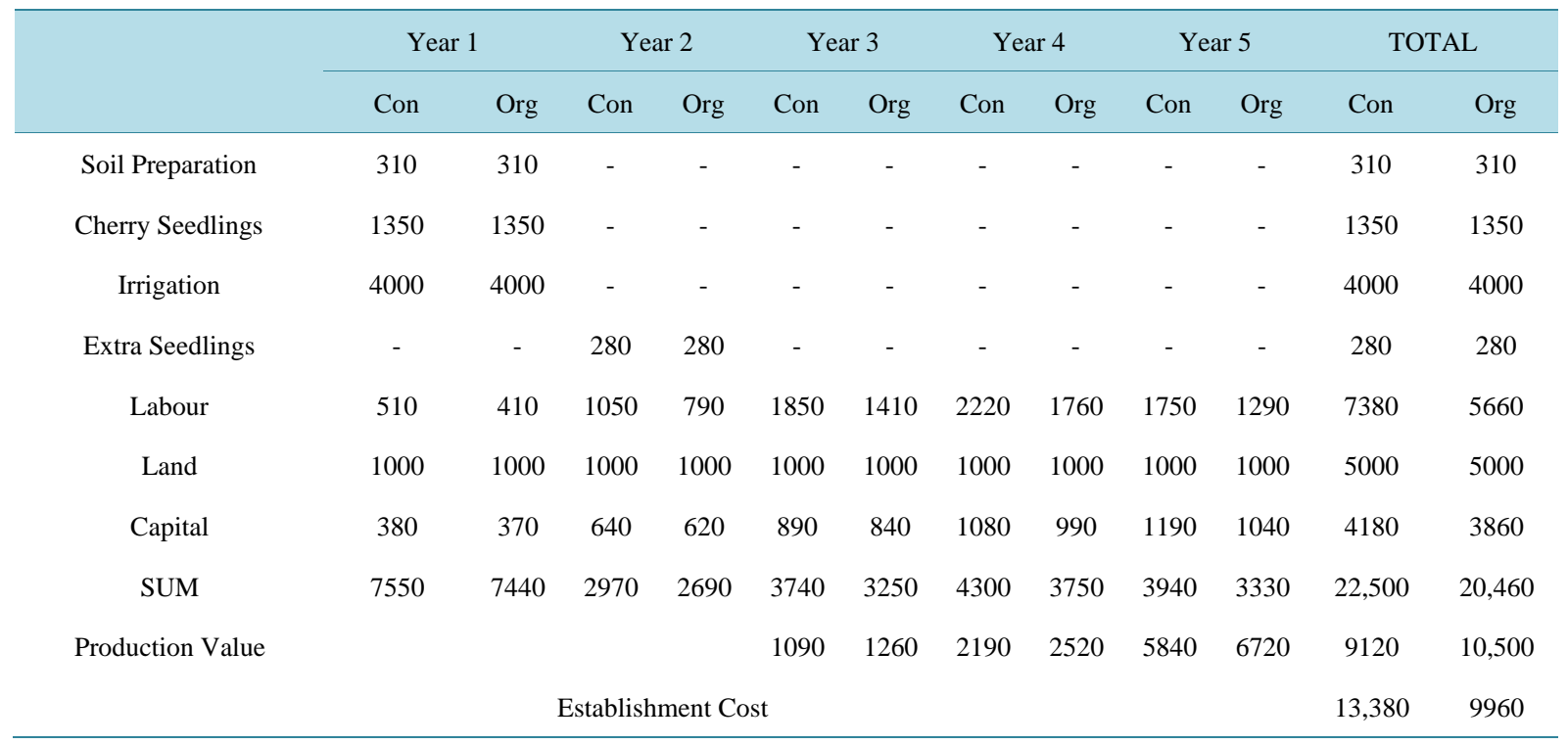

Table 2. Annual operating cost for conventional and organic cherry production.

\begin{tabular}{ccccc}
\hline & \multicolumn{2}{c}{ Conventional } & \multicolumn{2}{c}{ Organic } \\
\cline { 2 - 4 } & $€ /$ ha & $\%$ of total cost & $€ /$ ha & $\%$ of total cost \\
\hline Land & 7679 & & 6,131 & $16.31 \%$ \\
Labour & 1000.0 & $13.02 \%$ & 1000.0 & $35.94 \%$ \\
Family Labour & 3777.1 & $49.19 \%$ & 2203.4 & $53.81 \%$ \\
Hired Labour & 1996.2 & $52.85 \%$ & 1185.6 & $46.19 \%$ \\
Capital & 1780.9 & $47.15 \%$ & 1017.8 & $47.75 \%$ \\
Variable Capital & 2901.9 & $37.79 \%$ & 2927.2 & $76.83 \%$ \\
Fertilizers \& Pesticides & 2293.4 & $79.03 \%$ & 2249.0 & $52.60 \%$ \\
Diesel \& Lubricants & 1315.9 & $57.38 \%$ & 1183.0 & $8.64 \%$ \\
Irrigation & 160.6 & $7.00 \%$ & 194.4 & $9.59 \%$ \\
Certification & 394.1 & $17.18 \%$ & 215.7 & $5.28 \%$ \\
Other & 20.3 & $0.89 \%$ & 118.7 & $23.89 \%$ \\
Fixed Capital & 402.5 & $17.55 \%$ & 537.2 & $23.17 \%$ \\
\hline
\end{tabular}

\subsection{Yield Data}

Cherry farmers encounter two outstanding sources of yield risk. First, they face multi-year risk exposure, as the cherry crop is perennial, and yield can be expressed as a function of the age of the trees [17] [19]. Mithöfer and Wesseler [20] suggest that the relationship between the age of trees $(g)$ and yield $(u)$ can be described by a Hoerl function: $u=w g^{a} e^{k g}$. We estimated this function using data from the survey, expert opinions regarding cherry production and the ordinary least squares method for the corresponding coefficients $w, a$ and $k$. The estimated function is equal to $\ln (u)=2.4+2.4 * \ln (g)-0.146 * g$, with $\mathrm{R}^{2}=0.693$ and Adjusted $\mathrm{R}^{2}=0.646$.

Second, cherry farmers must embed in their estimates the annual variation of yield due to weather conditions [21]. The frequency of frosts is a critical factor that a farmer must seriously consider. Thus, the estimated yield 
from the Hoerl function was multiplied by a discrete empirical distribution to take into account the uncertainty of cherry yields [22]. This distribution was constructed using the percentage of the damage and the probability that this damage would occur. According to our survey, in 2007, the average yield reached $70 \%$ of the expected yields, as the damage was approximately 30\%. This yield was observed once in 6 years (during the 2000-2005 period). Similarly, the same frequency applies in the following cases: $45 \%$ of the expected yield in $2000,100 \%$ of the expected yield in $2001,60 \%$ of the expected yield in $2002,13 \%$ of the expected yield in $2003,42 \%$ of the expected yield in 2004 and, $70 \%$ of the expected yield in 2005 using information provided by the Hellenic Agricultural Insurance Organization.

In the case of the organic cherry yields, the estimation of the Hoerl function was not possible due to limited observations. However, our survey reveals that organic cherry yield is approximately $40 \%$ lower than conventional yield. Consequently, to extract the Hoerl function for organic cherry production, we subtract $40 \%$ of the conventional yields at each observation. Finally, unlike insurance compensation, the return of the value-added tax was incorporated into the gross revenue in both cases.

\subsection{Price Data}

To construct the price distribution for conventional cherries, we used the available data from the Hellenic Ministry of Rural Development and Food. These data include the annual average producer prices for the 1995-2006 period in current prices, which were converted to steady prices according to the agricultural output price indices of Eurostat (base year: 2006). After removing time trend effects, we found that the data follow the normal distribution with a mean value equal to $1.72 € / \mathrm{kg}$ and a standard deviation equal to $0.2(\mathrm{CV}=11.63 \%)$. As each element of the data reflects the average producer price for each year, using the above standard deviation for the price distribution that an individual producer faces would obviously lead to underestimation of the dispersion. The price data collected from the interviews support the above argument, as the coefficient of variation is much greater $(\mathrm{CV}=24.39 \%)$. To correct the underestimated value of the standard deviation, we applied a normal distribution with a mean value equal to $1.72 € / \mathrm{kg}$ and a standard deviation equal to 0.3 (equalling a $50 \%$ increase). Individuals with organic cherry expertise were asked to determine the mean value and the standard deviation of the price of organic cherries in their region. Their replies correspond to a truncated normal distribution with a mean value equal to $2.38 € / \mathrm{kg}$, a standard deviation equal to 0.7 , and a minimum price equal to $0.4 € / \mathrm{kg}$.

\section{Results}

Stochastic dominance analysis is applied to investigate the interest of farmers in the expansion of the cherry sector. Investment in either organic or conventional agriculture should improve both economic and environmental performance. Given the current economic crisis and the limited availability of agricultural funding, economic performance is crucial for Greek farmers, and improved competitiveness should be their core aim. Diversification into higher-value crops would be an option for a large number of small and medium farmers if they could manage the technical, financial and marketing requirements of the new cultivation. In this study, a stochastic efficiency with respect to a function analysis is applied to evaluate two investment options: an organic cherry orchard, and a conventional one. Furthermore, a sensitivity analysis is employed to examine the economic effect of the organic subsidy level.

The stochastic model estimates the probability of each NPV outcome occurring, providing an NPV range, with minimum, maximum and mean values. Simulated distributions of expected net returns were developed in a Simetar environment [22]. Simetar simulates a probability distribution of NPV based on the distributions of yield and price. A Monte Carlo simulation was used to determine the mean and variance of the NPV for conventional and organic cherry production (using 500 Monte Carlo iterations).

The cumulative distribution functions (CDFs) were constructed to demonstrate that the probability of a NPV (on the $\mathrm{Y}$-axis) for each activity was less than a particular CDF level (on the $\mathrm{X}$-axis). Although CDFs provide useful information on the profitability of the compared activities, the preferred activity for a certain decision maker depends also on his/her risk aversion. To determine the preferred alternative, stochastic dominance and SERF analyses were applied.

A crucial element in the formation of NPV is the level of organic subsidy. Under the previous Greek policy scheme, organic cherry farmers benefited from a $900 € /$ ha subsidy. However, after 2007, this subsidy was abolished. To investigate its importance, we applied a sensitivity analysis using various portions of the level of subsidy 
provided under the previous policy scheme.

The results of the simulation of the NPV for conventional cherry production show a $0.83 \%$ probability of a negative NPV (Table 3). The mean value is 15,266 €/ha, while the minimum and maximum NPV are -5334 $€ /$ ha and 34,709 €/ha respectively. The minimum values for organic farming with any subsidy level are greater, while the probability of a negative NPV varied from $0 \%$ with the $900 € /$ ha and $450 € /$ ha subsidy levels to $1.65 \%$ with the $150 € /$ ha subsidy level. On the other hand, the results from the simulation of NPV for organic cherry production without subsidy are not encouraging. The mean and the maximum values are much lower than those of conventional production (12,764 €/ha and 29,069 €/ha respectively), while the probability of negative NPV is much higher (3.51\%). Thus, the minimum value along with the relative risk are greater in organic than in conventional cherry farming (see Figure 1).

Table 3. Descriptive statistics and probability of a negative NPV for conventional and organic cherry production ( $€ / \mathrm{ha})$.

\begin{tabular}{ccccccc} 
& \multicolumn{9}{c}{ Organic Production } & Conventional Production \\
\cline { 2 - 6 } & No subsidy & $900 € /$ ha & $450 € /$ ha & $300 € /$ ha & $150 € /$ ha & 15266.83 \\
Mean & 12764.63 & 23713.76 & 18239.20 & 16414.34 & 14589.49 & 6551.13 \\
Standard Dev. & 6537.52 & 6537.52 & 6537.52 & 6537.52 & 6537.52 & 42.91 \\
CV & 51.22 & 27.57 & 35.84 & 39.83 & 44.81 & -5334.79 \\
Min & -4658.63 & 6290.50 & 815.93 & -1008.92 & -2833.78 & 34709.71 \\
Max & 29069.57 & 40018.70 & 34544.14 & 32719.28 & 30894.43 & 40044.50 \\
Range & 38,034 & 33728.20 & 33728.20 & 33728.20 & 33728.20 & $0.83 \%$ \\
\hline
\end{tabular}

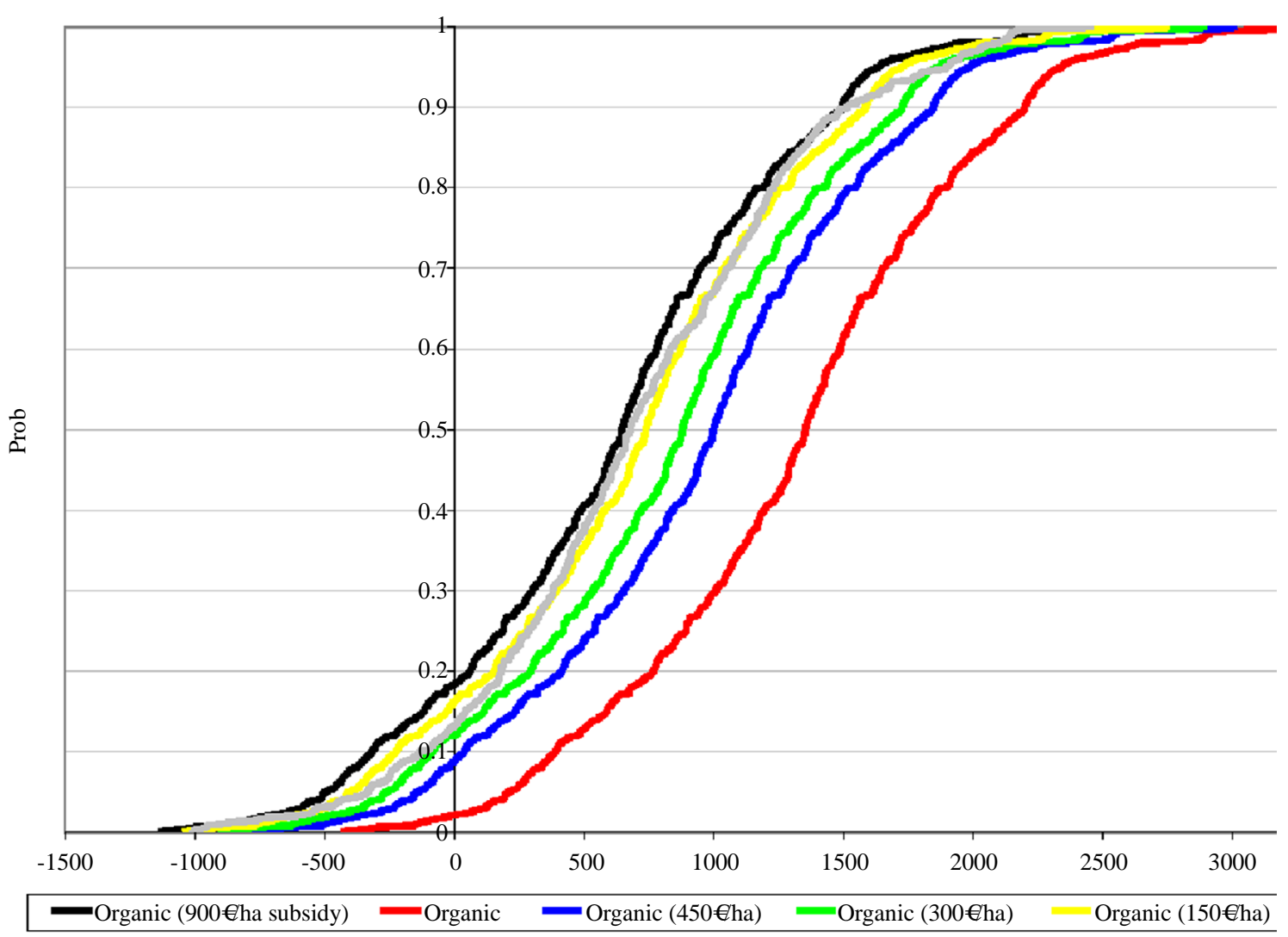

Figure 1. CDFs of conventional cherry production and organic cherry production at various subsidy levels. 
Under the previous organic payment scheme (900 €/ha subsidy level), organic cherry production yields higher economic results than conventional farming and bears zero probabilities of negative NPV. This is also the case under the 450 €/ha subsidy level scenario. The higher ranking of organic production is, however, not that obvious at lower levels of subsidy. Under the $150 € /$ ha level of subsidy scenario, the mean and the maximum values are lower than those of conventional farming, while the probability of negative NPV is higher (1.64\%).

As Figure 2 indicates, the CDF of the conventional farming alternative crosses with the CDFs of organic farming alternatives under the $450 € /$ ha level of subsidy. To determine the preferred alternative, a stochastic dominance analysis was applied. According to the results, the organic farming alternatives with 900, 450 and $300 € /$ ha levels of subsidy dominate the conventional cherry farming alternative in both lower and higher RACs (by level of preference). On the other hand, the ranking of conventional cherry production and organic cherry production with $150 €$ /ha and zero subsidy levels is different in the two RACs. Specifically, these two organic cherry production alternatives are higher in the higher RAC but lower in the lower RAC. This means that the organic alternatives are more risky, and they are preferred by risky investors.

As the stochastic dominance analysis provides answers only for the lower and upper RAC, a SERF analysis was applied to determine the preferred activity for all levels of risk aversion. SERF analysis reveals that organic cherry production with a subsidy level below $150 € /$ ha possesses a lower ranking than conventional production. However, the difference is very small in the case of the $150 € /$ ha level of subsidy (Figure 2).

Table 4 provides the NPV development for the particular investment options, organic or conventional cherry production, with reference to changing discount rates. Under the current financial crisis, the level of the discount rate is a crucial parameter for economic analysis. The greater the relevant uncertainty over the projected earnings, the greater the discount rate needed. In this respect, the sensitivity analysis indicates the tremendous effects of changes in the discount rate at the $10 \%$ and $12 \%$ level; as the discount rate increases, the level of NPV decreases significantly (see Table 4).

\section{Conclusions}

This work has aimed to evaluate two investment options, the establishment of an organic cherry orchard and the establishment of a conventional one. Stochastic efficiency with respect to a function (SERF) analysis was applied to compare the NPV of these investments, taking under consideration the risk and uncertainty associated with them.

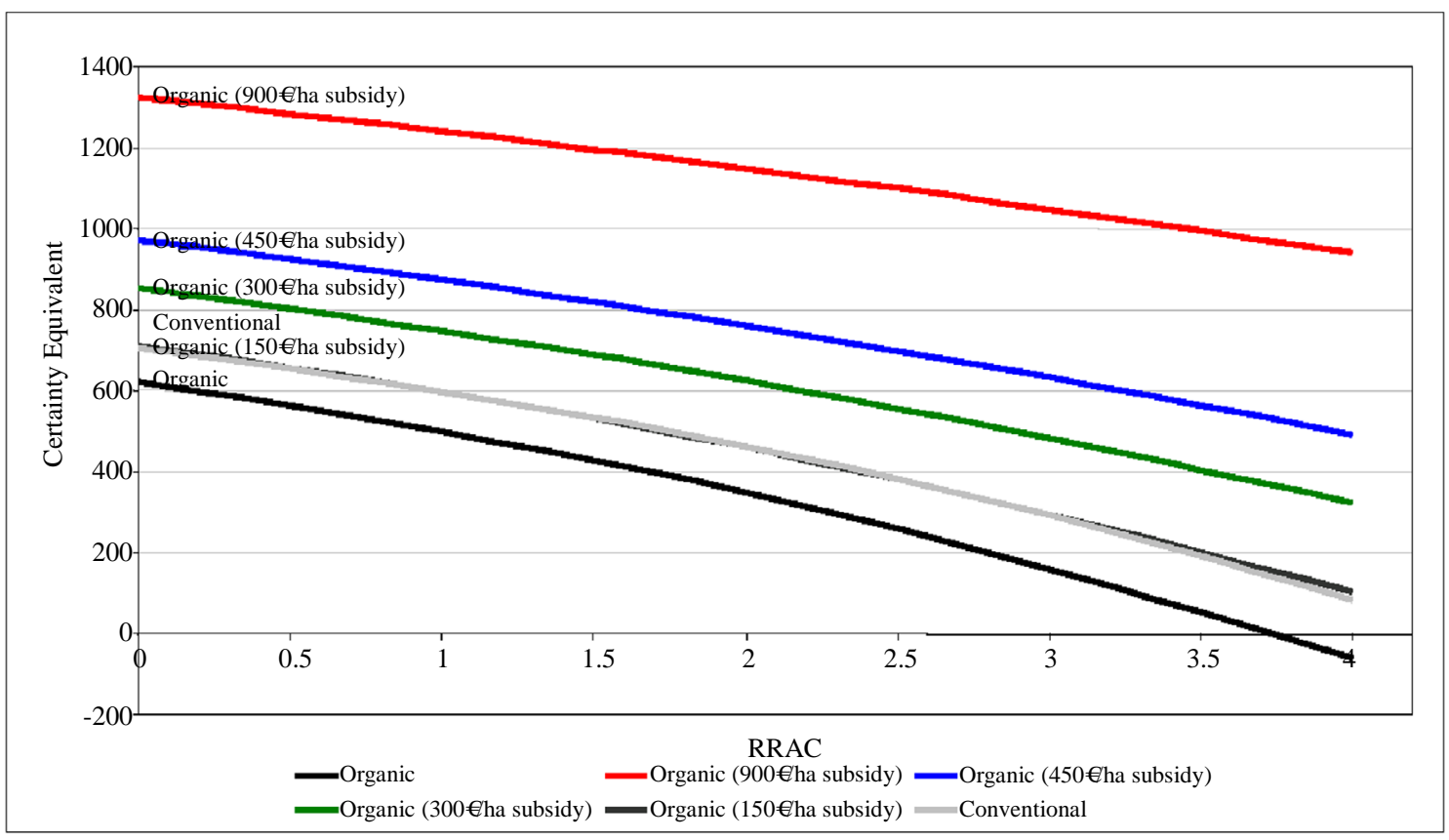

Figure 2. Stochastic efficiency with respect to a function for conventional production and organic production at various subsidy levels. 
Table 4. Descriptive statistics and probability of a negative NPV for conventional and organic cherry production (€/ha) under different discount rates.

\begin{tabular}{|c|c|c|c|c|c|c|c|c|c|}
\hline Investment Option & Subsidy Level & Discount Rate & Mean & Standard Deviation & $\mathrm{CV}$ & Min & Max & Range & $\operatorname{Prob}(X \leq 0)$ \\
\hline & - & $8 \%$ & 15,267 & 6551 & 43 & -5335 & 34,710 & 40,045 & 0.01 \\
\hline \multirow[t]{9}{*}{ Conventional } & - & $10 \%$ & 7852 & 5343 & 68 & -8643 & 23,856 & 32,499 & 0.06 \\
\hline & - & $12 \%$ & 2528 & 4479 & 177 & $-10,860$ & 16,338 & 27,198 & 0.29 \\
\hline & 0 & $8 \%$ & 12,765 & 6538 & 51 & -4659 & 29,070 & 33,728 & 0.04 \\
\hline & 0 & $10 \%$ & 6180 & 5333 & 86 & -7687 & 18,904 & 26,591 & 0.12 \\
\hline & 0 & $12 \%$ & 1448 & 4468 & 309 & -9786 & 12,636 & 22,422 & 0.39 \\
\hline & 900 & $8 \%$ & 23,714 & 6538 & 28 & 6290 & 40,019 & 33,728 & 0.00 \\
\hline & 900 & $10 \%$ & 15,701 & 5333 & 34 & 1833 & 28,425 & 26,591 & 0.00 \\
\hline & 900 & $12 \%$ & 9923 & 4468 & 45 & -1310 & 21,111 & 22,422 & 0.01 \\
\hline & 450 & $8 \%$ & 18,239 & 6538 & 36 & 816 & 34,544 & 33,728 & 0.00 \\
\hline \multirow[t]{8}{*}{ Organic } & 450 & $10 \%$ & 10,941 & 5333 & 49 & -2927 & 23,664 & 26,591 & 0.03 \\
\hline & 450 & $12 \%$ & 5685 & 4468 & 79 & -5548 & 16,873 & 22,422 & 0.10 \\
\hline & 300 & $8 \%$ & 16,414 & 6538 & 40 & -1009 & 32,719 & 33,728 & 0.00 \\
\hline & 300 & $10 \%$ & 9354 & 5333 & 57 & -4514 & 22,077 & 26,591 & 0.04 \\
\hline & 300 & $12 \%$ & 4273 & 4468 & 105 & -6961 & 15,461 & 22,422 & 0.18 \\
\hline & 150 & $8 \%$ & 14,589 & 6538 & 45 & -2834 & 30,894 & 33,728 & 0.02 \\
\hline & 150 & $10 \%$ & 7767 & 5333 & 69 & -6101 & 20,491 & 26,591 & 0.08 \\
\hline & 150 & $12 \%$ & 2860 & 4468 & 156 & -8373 & 14,048 & 22,422 & 0.26 \\
\hline
\end{tabular}

Results indicate that organic cherry production under the current policy scheme, which does not provide organic subsidies for farmers, yields lower expected NPV and a high probability of negative NPV. This is mainly the result of the price and yield uncertainty that characterises organic production. Low prices are partially explained by the fact that the market for organic cherries is not yet well developed in Greece and therefore most organic producers are forced to sell their products as conventional products. Under the present circumstances, the organic payment scheme is necessary to motivate farmers to switch to organic cherry farming. Under the previous policy scheme, which supported organic cherry producers with a subsidy equal to $900 €$ /ha, organic cherry production was by far a more attractive option for cherry farmers. The expected NPV stands at a high level, while the probability of negative NPV is much lower than that of conventional cherry production.

To explore the effect of the organic subsidy level on the NPV, we also applied a sensitivity analysis to the effect of subsidy level on NPV, considering policy schemes that provide different portions of the previous subsidy level. The sensitivity analysis indicates that the existence of a subsidy amounting to less than half of the subsidy that farmers received during the previous period makes organic cherry production a more appealing option for farmers. On the other hand, a low subsidy level of $150 € /$ ha makes the organic option of equal preference to a farmer. Therefore, while the subsidy of $900 € /$ ha was overly high, the decision to abolish organic subsidies for organic cherry producers was inappropriate. Even a much lower subsidy level could make organic cherry production an appealing option for farmers. Finally, the analysis also underlines the major effects of changes in the discount rate, which reflect ongoing risk and uncertainty. Under the current conditions of financial stress, the relative returns from agricultural investments avert farmers from investing in innovative agricultural options. However, agricultural policy makers have the responsibility to provide an investment climate that is conducive to sustainable agricultural investments.

An enabling environment for reorganisation and modernisation of the agricultural sector can create new economic opportunities for development within rural areas. Therefore, diversification into higher-value crops could 
be a promising option for a large number of small and average-sized farms, especially during the current economic crisis, advancing the climate-smart agricultural approach [23]. However, the option to invest in organic cherries is advisable only with the existence of organic subsidies. Organic cherry farmers encounter numerous constraints that limit their economic performance. There is a definite need for policy instruments that could improve the long-term confidence of farmers. Incentives for investments in organic cherry farming may involve measures that improve yields, create favourable market conditions that will lead to higher price premiums for organic products and support research and extension in organic agriculture.

The dynamic environment of the organic agriculture industry, in which uncertainty and risk are critical parameters, requires the use of appropriate tools that can assist both farmers and policy makers in making the appropriate investment decisions. In this respect, the further expansion of the cherry sector towards organic practices can improve economic and environmental sustainability and encourage rural development.

\section{References}

[1] European Commission (2010) An Analysis of the EU Organic Sector. Directorate General for Agriculture and Rural Development. http://www.ec.europa.eu/agriculture/analysis/markets/organic 2010 en.pdf

[2] Weibel, F.P., Willer, L., Tamm, C. and Schwartau, H. (2012) Organic Fruit Growing and Markets in Europe in the Early 2010s: Solutions, Challenges and Perspectives. The 2nd International Organic Fruit Research Symposium-ISHS, Organic Fruit 2012: From Research to Practice, Leavenworth, 18-21 June 2012.

[3] HMRDF (undated) Hellenic Ministry of Rural Development and Food, Statistical Data Series for Organic Agriculture and Animal Production in Greece http://www.minagric.gr

[4] Lin, B.-H., Yen, S.T. and Huang, C.-L. (2008) Demand for Organic and Conventional Fresh Fruits. The 2008 Annual Meeting of the American Agricultural Economics Association, Orlando, 27-29 July 2008.

[5] NAGREF-National Agricultural Research Foundation-National Agricultural Research Agricultural Economics and Policy Research Institute (2007) Report 2.3.1 Cherries Sector. Search for Innovative Occupations of Tobacco Producers Measure 9, Reg. EU 2182/02, Athens. (in Greek)

[6] NSSG (undated). National Statistical Service of Greece Statistics for Agriculture. http://www.statistics.gr

[7] Usenik, V., Fabric, J. and Stampar, F. (2008) Sugars, Organic Acids, Phenolic Composition and Antioxidant Activity of Sweet Cherry (Prunus avium L.). Food Chemistry, 107, 185-192. http://dx.doi.org/10.1016/j.foodchem.2007.08.004

[8] Conte, A., Scrocco, C., Lecce, L., Mastromatteo, M. and Del Nobile, M.A. (2009) Ready-to-Eat Sweet Cherries: Study on Different Packaging Systems. Innovative Food Science and Emerging Technologies, 10, 564-571. http://dx.doi.org/10.1016/j.ifset.2008.12.005

[9] Hardaker, J.B., Richardson, J.W., Lien, G. and Schumann, K.D. (2004a) Stochastic Efficiency Analysis with Risk Aversion Bounds: A Simplified Approach. Australian Journal of Agricultural and Resource Economics, 48, 253-270. http://dx.doi.org/10.1111/j.1467-8489.2004.00239.x

[10] Hardaker, J.B., Huirne, R.B.M., Anderson, J.R. and Lien, G. (2004b) Coping with Risk in Agriculture. 2nd Edition, CABI Publishing, Wallingford. http://dx.doi.org/10.1079/9780851998312.0000

[11] Aditto, S. (2011) Risk Analysis of Smallholder Farmers in Central and North-East Thailand. PhD Thesis, Lincoln University, Lincoln.

[12] Tzouramani, I., Karanikolas, P. and Alexopoulos, G. (2008) Risk and Income Risk Management Issues for Organic Crops in Greece. Proceedings of the 108th EAAE Seminar. Income Stabilization in a Changing Agricultural World: Policy and Tools, Warsaw, 8-9 February 2008, 186-198.

[13] Tzouramani, I., Sintori, A., Liontakis, A., Karanikolas, P. and Alexopoulos, G. (2011) An Assessment of the Economic Performance of Organic Dairy Sheep Farming in Greece. Livestock Science, 141, 136-142. http://dx.doi.org/10.1016/j.livsci.2011.05.010

[14] Hanoch, G. and Levy, H. (1969) The Efficient Analysis of Choices Involving Risk. Review of Economic Studies, 36, 335-346. http://dx.doi.org/10.2307/2296431

[15] Hirshleifer, J. and Riley, J.G. (1992) The Analytics of Uncertainty and Information. Cambridge University Press, Cambridge.

[16] Richardson, J.W., Schumann, K. and Feldman, P. (2006) Simulation \& Econometrics to Analyze Risk. Department of Agricultural Economics, Texas A\&M University, College Station.

[17] Kitsopanidis, G., Zioganas, C. and Vasilakakis, M. (1999) Polomogy Contribution in Agricultural Development in Less Favoured Areas of Main Producing Areas of Greece. Agricultural University of Thessaloniki, Thessaloniki. (in Greek) 
[18] Pontikis, A. (1996) Specialized Pomology, Part B. Stamoulis Publications, Athens. (in Greek)

[19] Rahim, A.H., Van Ireland, E.C. and Wesseler, J. (2007) Economic Incentives for Abandoning or Expanding Gum Arabic Production in Sudan. Forest Policy and Economics, 10, 36-47. http://dx.doi.org/10.1016/j.forpol.2007.02.002

[20] Mithöfer, D. and Wesseler, J. (2002) When Will Farm-Households Consider to Plant Domesticated Indigenous Fruit Trees? A Real Options Approach. The International Conference: Risk and Uncertainty in Environmental and Resource Economics, Wageningen, June 2002.

[21] Vasilakakis, M. (2007) General and Specialized Pomology. Gartaganis Publications, Thessaloniki. (in Greek)

[22] Simetar (2008) Simulation and Econometrics to Analyze Risk. Department of Agricultural Economics, Texas A\&M University, College Station.

[23] FAO (2012) The State of Food and Agriculture: Investing in Agriculture for a Better Future. http://www.fao.org/publications/sofa/en/ 